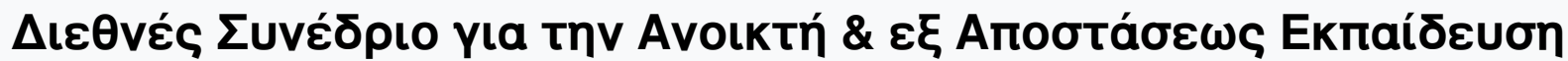

Tón. 8, Ap. 1A (2015)

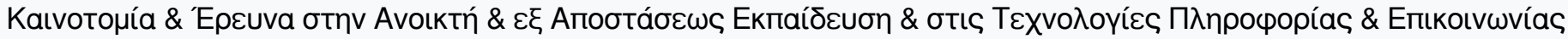

\section{Прakuiká}

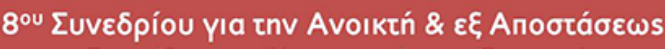

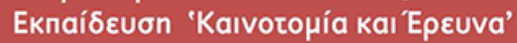

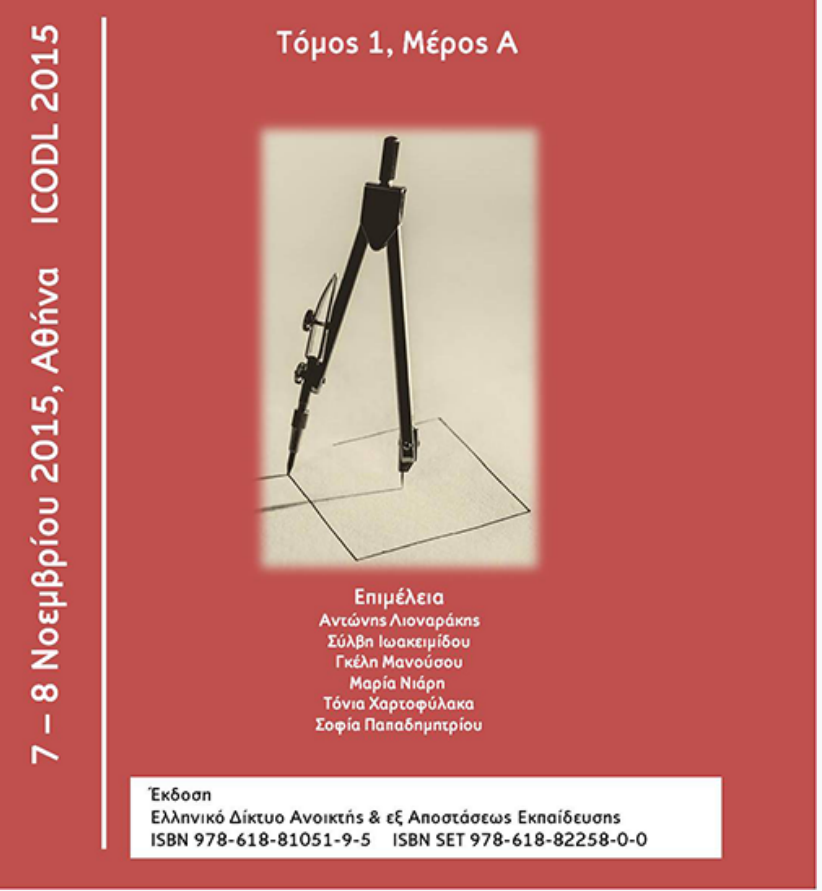

Open courses in a Greek higher education institution: faculty views and attitudes

Nikolaos Avouris, Vassilios Komis, John Garofalakis doi: $10.12681 /$ icodl. 19 


\title{
Open courses in a Greek higher education institution: faculty views and attitudes
}

\author{
Nikolaos Avouris \\ University of Patras, Greece \\ avouris@upatras.gr
}

\author{
Vassilios Komis \\ University of Patras, Greece \\ komis@upatras.gr
}

\author{
John Garofalakis \\ University of Patras, Greece \\ garofala@ceid.upatras.gr
}

\begin{abstract}
"Open Courses", has been a large scale initiative to develop open courseware in Greek higher education. As the project has come to its end, a first evaluation of the outcomes is attempted in this paper at the level of one of the participating universities. The University of Patras has been a major partner in this project. It has been the Greek institution with the higher number of open courses developed in the frame of it. So it is worth looking closely into the produced results and in particular the views and attitudes of the faculty that participated in the process. In this paper, we report on the findings of a survey that was conducted during the final phase of the project. This survey asked key faculty members that participated in the action to provide their view on the experience and make suggestions on the future of open courseware in the University.
\end{abstract}

Key-words: open courseware, higher education

\section{Introduction}

MOOCs (Massive Open Online Courses) and other initiatives for developing open learning material are well established and their strategic role is further recognized in higher education institutions around the world. Allen and Seaman (2014), in a recent report on tracking online education in US universities, observe that while ten years back less than $50 \%$ of all higher education institutions reported online education as critical to their long-term strategy, now this number is close to $70 \%$. This, despite the fact that not many institutions (just 5\% according to the same survey), are putting the necessary effort and resources to develop MOOCs themselves.

Holland \& Tirthali (2014) in their research on the future of such learning approaches in higher education observe that the infrastructure and effort that has been put into such initiatives are not likely to disappear. So, while it is debatable if MOOCs as they currently stand persist into the future, there is no doubt that online and hybrid learning are well accepted and that such approaches have catalyzed a shift in stance by many institutions around the world.

\section{Context of the study}

In this context of strategy redefinition at the institutional level and concerns about possible revolutionary changes due to these advances (Epelboin, 2014, Cooper \& Sahami, 2013), many universities in Greece in the last 3 years embarked in a large scale project that had the objective to open up learning material in the form of open courseware. Most Greek higher education institutions participated in this action that produced a large number of open courses. Many of these courses contain videos of lectures that together with the course material are made available to a wide audience under creative commons licenses. 
The overall budget of this action that was supported by structural European and national funds was around 20 million euros. 26 (76\%) out of 34 Greek higher education institutions participated in the action, producing 2160 open courses, according to the figures of the national repository of open courseware opencourses.gr. By looking closely into the participation of the institutions in the project one observes that Technological Educational Institutes (TEI), that are mostly focused on applied sciences and skills development, participated more actively than universities on average. In particular the number of courses developed per faculty members in TEIs was 0.45 while the same figure for the universities was just 0.10 . The overall figure for all institutions was 0.14 (10959 faculty members produced 2160 open courses).

The University of Patras was the university that produced the highest number of open courses in the project, 335 courses overall (15\% of the total). It also had high ratio of courses per faculty member ( 0.45 courses per faculty member). In Avouris et al. (2015) there is a report on the difficulties and the lessons learned during the initial phases of the project. It should be stressed that this university has an active community supporting online learning and development of online learning material, as the usage statistics of the institutional learning management system demonstrate (fig.1).

In this paper, we report on the views of the faculty members involved in the process, as expressed in a questionnaire distributed to active faculty members during the final semester of the project (spring semester of academic year 2014-2015).

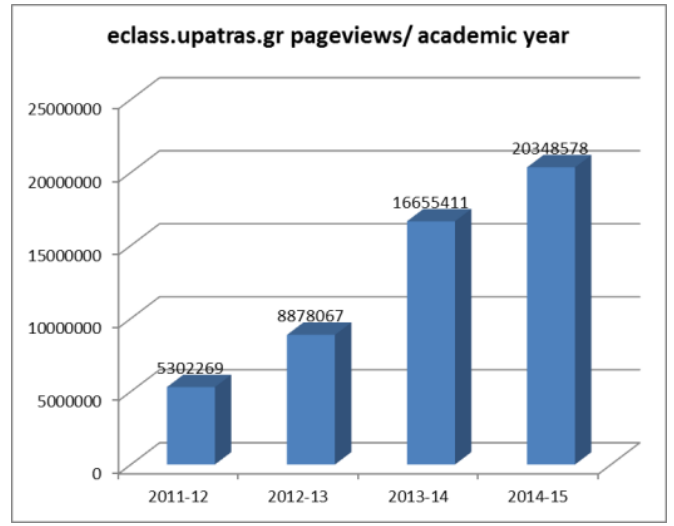

Fig.1 Usage of the learning content management system eclass.upatras.gr during the last three academic years at the University of Patras

\section{The study}

At the end of the Open Courses Project at the University of Patras, a survey was conducted with the objective of capturing the views of faculty members that have participated in the project. The questionnaire was inspired by the 10 year long survey of online education in US universities and colleges (see latest report by Allen \& Seaman, 2013), and was adapted to the experience of this particular project and university. It included an open question on the future of open courseware in the university, relating to institutional strategy. The questionnaire was anonymously answered by 23 faculty members (11\%), from around 200 active faculty members who were provided with access to it.

The 21 questions were answered using a Linkert 5 point scale $(5=$ strongly agree, $4=$ agree, $3=$ neutral, $2=$ disagree, $1=$ strongly disagree), with an additional open question on the future of open courseware at the university. We provide next the questions and the mean value of the received replies per question.

\section{The views of the faculty}


The questionnaire was structured in five sections: View over the project, view over the open courseware, view over the related policies, view over the envisaged use and student benefits, and view over barriers for adoption.

(a) View over the project

Q1. Do you consider the participation of your Department in the project satisfactory? Response $=$ neutral $(3.17$, stdev $=1.30)$

Q2. The support you had from the project team was sufficient? Response=agree (4.36, stdev=0.70)

Q3. Is the project outcome in the form of Open Courses satisfactory given the allocated effort and resources ? Response $=$ agree $(3.87$, stdev $=0.92)$

From the replies to this group of questions it is evident that the faculty was not happy with the participation of their department in the project. On the other hand, they have a positive view over the project outcome and a strongly positive view of the support team. It should be mentioned that a two level support team was set up, one at institutional level, to manage and maintain infrastructure and produce video lectures, and one at department level, to support faculty with producing learning material.

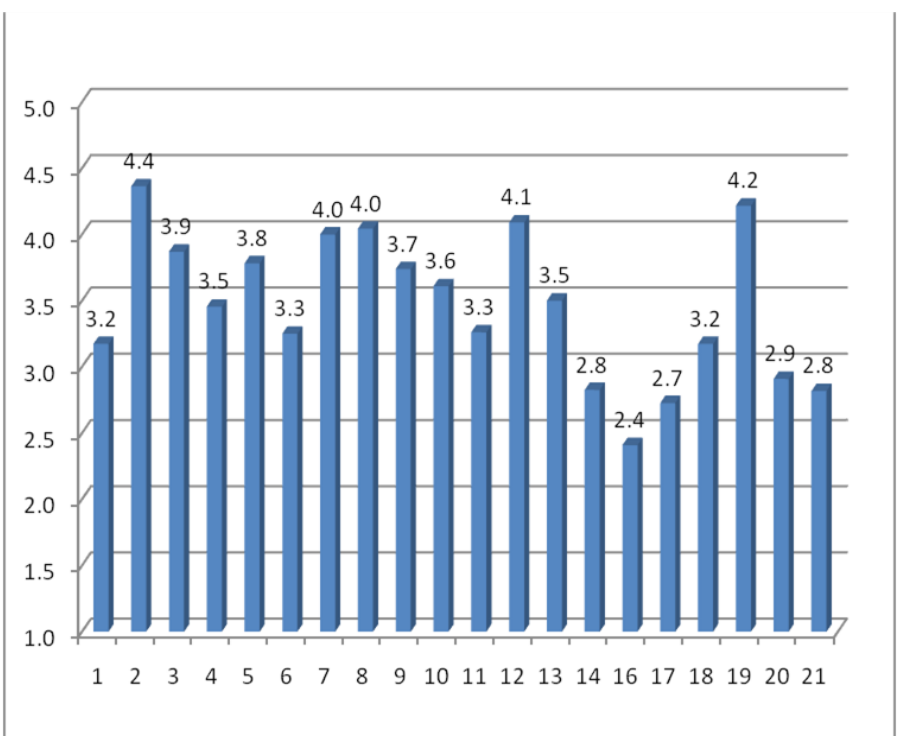

Fig.2 Average values of replies to the 21 questions of the questionnaire (range of replies $5=$ strongly agree, $4=$ agree, $3=$ neutral, $2=$ disagree, $1=$ strongly disagree).

(b) View over open courseware

Q4. Sustainability of Open Courses: do you believe that open courses is a viable way to offer education? Response=neutral-agree $(3.45$, stdev $=1.01)$

Q5. The open courses are appropriate way for institutions to learn about online pedagogy ; Response $=$ agree $(3.78$, stdev $=1.00)$

Q6. Open courses in your opinion support the University to attract higher-level students? Response $=$ neutral $(3.25$, stdev $=1.25)$

Q7. Open courses help students understand the benefits of online instruction? Response $=$ agree $(4.00$, stdev $=0.90)$

Q8. Open courses will support training of our graduates? Response=agree (4.04, stdev $=0.71$ )

Q9. Open courses content could be used for students' assessment? Response=agree $(3.74$, stdev $=1.32)$

Q10. Do you think it is possible to adapt the open courseware to different user needs? Response=agree $(3.61$, stdev $=1.20)$

This group of questions attempt to capture faculty views on open courseware sustainable use. The faculty expressed concerns about sustainability of open courses, as 
they feel that there is a lot of effort needed to maintain open online learning material. They doubt the use of open courseware for the university to attract higher level students. This is reflecting the current economic crisis situation in which students' criteria for university selection are mostly related to location of the institution rather than quality of education. On the other hand the responders share the view that open courseware will support training of graduates, while it will play a positive role in helping students understand the benefits of online instruction.

\section{(c) View over policies}

Q11. Open courses have in your opinion contributed to the development and implementation of innovative teaching and learning methods? Response=neutral (3.26, stdev=1.01)

Q12. Development of open courses should be part of institutional long term strategy? Response $=$ agree $(4.09$, stdev $=0.87)$

Q13. Your institution has supported effectively open courses? Response $=$ neutral-agree (3.50, stdev $=1.14)$

Q14. Do you think the development of open courses should be a criterion for faculty promotions? Response=agree $(3.87$, stdev $=0.92)$

In relation to policies there is agreement that development of open courseware should be part of institutional long term strategy, while there is less agreement on current support by the institution. When it comes to the question of using development of open courses as a criterion for faculty promotion it seems that this group of faculty shares this view, as expected, since they are themselves involved in open learning material development and therefore they see a benefit in this policy. However they are not positive in sharing the view that the online courses have contributed in implementing innovative teaching and learning methods, as currently the online courses have not yet being used as means for changing their teaching and learning practices.

\section{(d) View over students benefits}

Q15. What do you consider a sufficient number of students following your open course? Response $=50$ to $100($ stdev $=0.96)$

Q16. Do you think that students will derive benefit from following the open course instead of class teaching? Response $=$ disagree $(2.41$, stdev $=0.92)$

Q17. Do you incorporate ways of assessing learning outcome in your courses? Response $=$ neutral $(2.73$, stdev $=1.52)$

In relation to students' benefit from the online courseware, first there low expectation on the number of students following the course, on average 50 to 100 students following the online course is considered a satisfactory number. This is a surprising reply as the potential outreach of the developed online material is usually beyond the number of the face to face students of the university course. There is a disagreement on the idea of substituting the class teaching with online course, while there has not been effort put in incorporating learning outcome assessment methods in the online course. It should be mentioned that the focus of this particular project, was mostly on opening learning material rather than delivering a fully-fledged online course, which includes learning assessment.

\section{(d) Barriers to adoption}

Q18. Faculty acceptance of using digital media in education has increased after the experience of development of open courses? Response=neutral $(3.17, \mathrm{stdev}=0.94)$ 
Q19. Do you think that reservations against digital media in education by faculty is an obstacle for further development of online teaching? Response=agree (4.22, stdev $=0.74$ )

Q20. The reason for low effectiveness of online teaching you consider the lack of discipline framework? Response $=$ neutral $(2.91$, stdev $=1.41)$

Q21. You consider lower retention rate as a barrier to effective online teaching? Response $=$ neutral $(2.82$, stdev $=1.05)$

In relation to possible barriers to widespread adoption of online learning, the responders think that reservations against digital media in education by faculty are an obstacle for development of online teaching. This is strongly expressed and is in line with the response by stakeholders in US universities (Allen, \& Seaman, 2013). On the other hand, they do not fully share the view that faculty acceptance of using digital media has increased after development of open courses, the same applies on the view that the low effectiveness of online teaching is due to lack of discipline framework and that the barrier to effective online teaching is lower retention rate, as perhaps there is not enough evidence available for these two views, in the specific group of responders.

\section{The future of Open Courseware: faculty views}

One final open question concerned suggestions on future Open Courseware actions. 12 participants in the survey (52\%) have responded to this question and made overall 35 suggestions. The most frequent suggestions concerned (a) Provision of incentives to faculty for participation in the action (3 times), (b) Emphasis on blended learning approaches (3 times), (c) Focus on e-assessment (2 times), (d) development of more interactive activities in the open courses (2 times), (e) The importance of training of the faculty for development of open courseware (2 times).

In general the suggestions made concerned organizational issues of open courseware actions, and use of open courseware, ideas for development of new open courses, and ideas for new features and on policies concerning open courseware by the University. In more detail, we present next the suggestions made.

\section{Organizational issues, the process of development of opne courseware}

1.1 Provide incentives for instructors (e.g. remuneration) $* 3$

1.2 Use structured instructional design method for development (e.g ADDIE model)

1.3 Define Evaluation metrics (e.g. acceptance and usage measure)

1.4 Training of all participants in open courseware development $* 2$

1.5 Intra-university collaboration in development of open courseware

1.6 Better collaboration between support staff and instructors

1.7 Support for maintenance and improvement of open courseware

2. On the use of open courseware

2.1 Put more emphasis on blended learning, especially for crowded courses *3

2.2 Flipped classroom design

2.3 Focus on e-assessment $* 2$

2.4 Self-assessment support

2.5 More focus on interactive activities, move beyond content $* 2$

2.6 Open advanced courses to be given as optional courses to other university students

2.7 Open courseware to be related to existing curricula

\section{On the content of open courseware}


3.1 Development of Open courses in Greek culture (language, literature, history, archeology) in English for international audience

3.2 Translation of successful MOOCS

3.3 Courses beyond current curriculum

3.4 Development of inter-disciplinary courses in areas of general interest

3.5 Open courses for vocational training and skills certification (e.g. chemistry english terminology, water quality)

3.6 Introductory open courses for students of secondary education

\section{Technical issues, new features}

4.1 Tagging of open courseware for free search in content

4.2 Adaptive user access

4.3 Student registration system

4.4 Mechanisms for dissemination and publicity of courses

4.5 Development of tools for e-assessment (e-examination)

\section{On policies}

5.1 Policies for adoption of e-assessment

5.2 Faculty evaluation and promotion to include OCW development criterion

5.3 All compulsory courses to have open course online component

5.4 Encouragement of faculty members for participation in production of open courseware

\section{Conclusions}

The presented here results of the survey provide a rich insight in the concerns and expectations of faculty members that have been actively involved in development of open learning material. It is the first such report on views of such group in a Greek higher education institution. At the same time they express faculty concerns about the policies and institutional strategies and on the threats imposed by the overall context of higher education at home and internationally. They reflect the views and attitudes of faculty members of a university in crisis, due to the economic constraints and international competition. On the other hand the richness of ideas on the future use of this approach, and on the possible Greek strengths against international competition (e.g. in culture and humanities) demonstrate that in the faculty there is a positive attitude and a spirit of moving on using strengths and opportunities that technology provides us with. Let us hope that in the near future institutional and national policies in this issue will support these aspirations.

\section{References}

Allen, I. E., \& Seaman, J. (2013). Changing Course: Ten Years of Tracking Online Education in the United States. Sloan Consortium. PO Box 1238, Newburyport, MA 01950. Retrieved from: http://sloanconsortium.org

Avouris N., Komis V., Garofalakis J., (2015), Opening up University Courseware: Lessons learned, Proceedings EDULEARN 2015, 7th Int. Conference on Education and New Learning Technologies, IATED Publ., pp. 7585-7589. Barcelona, July 2015

Cooper, S., \& Sahami, M. (2013). Reflections on Stanford's MOOCs. Communications of the ACM, $56(2), 28-30$.

Epelboin, Y. (2014). MOOC 2014: should universities enter the competition?. EUNIS 2014 Congress June 11-13, Umeå University (Sweden), available from: http://www.eunis.org/erai/2014-1/

Hollands, F. M., \& Tirthali, D. (2014). MOOCs: Expectations and reality. Center for Benefit-Cost Studies of Education, Teachers College, Columbia University. retrieved from: https://www- 
$8^{\text {th }}$ International Conference in Open \& Distance Learning - November 2015, Athens, Greece - PROCEEDINGS

test.delta.ncsu.edu/assets/MOOCs_Expectations-and-Reality.pdf

\section{Acknowledgement}

Special thanks are due to the Open Courses project team of the University of Patras, for their dedication to the project mission and for contributing to such a wonderful experience 